\title{
Chemotherapy with 5-fluorouracil, cisplatin and streptozocin for neuroendocrine tumours
}

\author{
NC Turner', SJ Strauss', D Sarker', R Gillmore', A Kirkwood², A Hackshaw², A Papadopoulou ${ }^{3}$, J Bell ${ }^{3}$, \\ I Kayani ${ }^{4}$, C Toumpanakis ${ }^{5}$, F Grillo ${ }^{6}$, A Mayer', D Hochhauser ${ }^{1,7}$, RH Begent ${ }^{1,7}$, ME Caplin ${ }^{5}$ and T Meyer ${ }^{*, 1,7}$ \\ 'Department of Oncology, UCL Medical School, Royal Free Campus, London, UK; ${ }^{2}$ Cancer Research UK and UCL Cancer Trials Centre, London, UK; \\ ${ }^{3}$ Department of Radiology, Royal Free Hospital, London, UK; ${ }^{4}$ Department of Radiology, University College Hospital, London, UK; ${ }^{5}$ Department of \\ Gastroenterology, Royal Free Hospital, London, UK; ${ }^{6}$ Department of Pathology, UCL Medical School, Royal Free Campus, London, UK; ${ }^{7}$ Department of \\ Oncology, UCL Cancer Institute, London, UK
}

BACKGROUND: The role of chemotherapy for neuroendocrine tumours remains controversial and there is no standard regimen. METHODS: We report the outcome for a consecutive series of chemonaive patients with metastatic or locally advanced neuroendocrine tumours treated with a combination of 5-fluorouracil $\left(500 \mathrm{mg} \mathrm{m}^{-2}\right)$, cisplatin $\left(70 \mathrm{mg} \mathrm{m}^{-2}\right)$ and streptozocin $\left(1000 \mathrm{mg} \mathrm{m}^{-2}\right.$ ) (FCiSt) administered three weekly for up to six cycles. Patients were assessed for radiological response, toxicity and survival.

RESULTS: In the 79 patients assessable for response, treatment with FCiSt was associated with an overall response rate of 33\% (38\% for pancreatic primary sites and $25 \%$ for non-pancreatic primary sites). Stable disease occurred in a further $5 \mathrm{I} \%$, with progression in $16 \%$. The median time to progression was 9.1 months and median overall survival was 31.5 months. The most common grade $3-4$ toxicity was neutropaenia (28\% patients) but grade 3-4 infection was rare (7\%). The most frequent non-haematological grade 3-4 toxicity was nausea and vomiting (17\%). Prognostic factors included Ki-67, mitotic index, grade and chromogranin A, whereas response to chemotherapy was predicted by mitotic index, grade and $\alpha$-fetoprotein.

CONCLUSION: FCiSt is an effective regimen for neuroendocrine tumours with an acceptable toxicity profile. Grade and mitotic index are the best predictors of response.

British Journal of Cancer (2010) 102, II06- III2. doi:10.1038/sj.bjc.66056I8 www.bjcancer.com

Published online 16 March 2010

(c) 2010 Cancer Research UK

Keywords: chemotherapy; NETs; Ki-67; mitotic index

Neuroendocrine tumours (NETs) are a heterogeneous group of malignancies that arise from various sites in the body, most commonly the gastrointestinal (GI) tract. The clinical course varies from a highly aggressive disease with a median survival of around 6 months in patients with metastatic high-grade tumours, to a more indolent process in which patients live with their disease for up to 20 years (Pape et al, 2008a, b; Yao et al, 2008). Recent data suggest that the incidence of NETs has increased fivefold over the past 30 years and is now 5.25 per 100000 . Moreover the long survival times mean that the prevalence of NETs is now greater than that of other GI tumours including pancreatic and oesophagogastric cancers (Yao et al, 2008).

Surgery is the only curative intervention, but in the majority of cases metastasis has already occurred at the time of presentation and palliative measures are required. For functional tumours, hormone-related symptoms can be controlled with somatostatin analogues, although whether somatostatin analogues influence tumour growth is not clear. Loco-regional interventions including embolisation, ablation or debulking surgery have also been used to ameliorate symptoms associated with hormone production.

*Correspondence: Dr T Meyer, UCL Cancer Institute, 72 Huntley Street, London WCIE 6BT, UK. E-mail: t.meyer@ucl.ac.uk

Revised 28 January 2010; accepted 21 February 2010; published online 16 March 2010
A variety of systemic chemotherapy regimens have been explored (Toumpanakis et al, 2007) but there is no accepted standard of care. The initial studies by Moertel et al $(1980,1992)$ using streptozocin in combination with fluorouracil or doxorubicin in pancreatic NETs gave encouraging response rates of over $60 \%$ based on reduction of hepatomegaly and biochemical response. However subsequent studies applying more rigorous objective response criteria report response rates between 6 and $45 \%$ for pancreatic NETs (Eriksson et al, 1990; Cheng and Saltz, 1999; Kouvaraki et al, 2004) and 15-30\% for non-pancreatic NETs (Engstrom et al, 1984; Bukowski et al, 1987; Sun et al, 2005). The combination of cisplatin and etoposide has also been evaluated, and high response rates have been reported for poorly differentiated tumours (Moertel et al, 1991; Mitry et al, 1999; Fjallskog et al, 2001). These studies have also included a small number of patients with well-differentiated endocrine cancers (WDECs) who had failed previous chemotherapy and achieved response rates ranging from 9 to $45 \%$. However cisplatin has never been systematically tested as first-line therapy in a large series of WDECs.

Here we report for the first time, the clinical outcome of a series of 82 consecutive patients with advanced NETs prospectively collected over a period of 8 years, who were all treated with the novel combination: 5 -fluorouracil $\left(500 \mathrm{mg} \mathrm{m}^{-2}\right)$, cisplatin $\left(70 \mathrm{mg} \mathrm{m}^{-2}\right)$ and streptozocin $\left(1000 \mathrm{mg} \mathrm{m}^{-2}\right)$ (FCiSt) on day 1 of a three weekly cycle. Patients were assessed for radiological 
response, toxicity and survival, and prognostic and predictive factors associated with response to chemotherapy were elucidated.

\section{PATIENTS AND METHODS}

\section{Patients}

Patients with advanced NETs treated with FCiSt chemotherapy at the Royal Free Hospital were identified from a prospective database. Between May 1999 and April 2008, 98 consecutive patients were treated of which 82 were included in the analysis. Reasons for exclusion were chemotherapy given with adjuvant intent $(n=2)$, previous chemotherapy or chemoembolisation $(n=12)$, no evaluable imaging or clinical follow-up $(n=2)$. Patients who had undergone external beam radiotherapy earlier were included in the study, provided that disease was measured outside the radiation field. Patients with tumours of all primary sites and with unknown primary tumours were included in the analysis. Two patients received subcutaneous octreotide therapy concurrently with chemotherapy. Indications to commence chemotherapy were radiological progression $(n=17)$, tumour grade $(n=25)$, progressive symptoms related to increasing tumour burden (rather than hormone secretion) $(n=36)$ or intention of downstaging the disease for surgery $(n=4)$.

\section{Chemotherapy}

FCiSt chemotherapy consisted in order: calcium folinate $45 \mathrm{mg}$ over $2 \mathrm{~h}$, 5 -fluorouracil $500 \mathrm{mg} \mathrm{m}^{-2}$ by slow bolus, streptozocin $1000 \mathrm{mg} \mathrm{m}^{-2}$ in $1000 \mathrm{ml} 0.9 \%$ saline (Nsaline) over $2 \mathrm{~h}$, mannitol $20 \mathrm{~g}$ in $200 \mathrm{ml}$ Nsaline over $30 \mathrm{~min}$, cisplatin $70 \mathrm{mg} \mathrm{m}^{-2}$ in $1000 \mathrm{ml}$ Nsaline over $2 \mathrm{~h}$ followed by post-hydration. Chemotherapy was administered every 21 days for a maximum of 6 cycles. For patients with glomerular filtration rate (GFR), assessed by ${ }^{51} \mathrm{Cr}-$ EDTA clearance, less than $60 \mathrm{ml} \mathrm{min}^{-1}$, either at baseline or that developed during chemotherapy, cisplatin was substituted with carboplatin AUC $5 \mathrm{mg} \mathrm{ml}^{-1} \mathrm{~min}^{-1}$ (Calvert formula) referred to as FCaSt. Cycles of chemotherapy were delayed until recovery of neutrophil count $\geqslant 1.0 \times 10^{9}$ per litre and platelet count $\geqslant 100 \times 10^{9}$ per litre. Doses of all drugs were reduced by $20 \%$ following grade 3 non-haematological toxicity or treatment delay due to myelosuppression. Patients who had not progressed after three cycles of chemotherapy continued to six cycles, in the absence of unacceptable toxicity.

\section{Response and toxicity assessment}

Baseline scans were performed within 6 weeks before starting chemotherapy. Response was assessed by CT scan after three cycles of chemotherapy, with patients continuing to six cycles of chemotherapy in the absence of progression. Further response assessment was by CT scan after completion of chemotherapy, and at three monthly intervals until progression. Three patients were not assessable for response after receiving two, three and six cycles of chemotherapy respectively. Response was determined by two independent radiologists using RECIST criteria, with best response reported without a subsequent confirmation scan. Time to response (TTR) was recorded as the time from the date of commencing chemotherapy to demonstration of objective response assessed by independent review, and duration of response from the date of scan confirming objective response to disease progression. Progression-free survival (PFS) was recorded as the time from the date of commencing chemotherapy to demonstration of objective disease progression or death. Overall survival (OS) was recorded as the time from the date of commencing chemotherapy to the patient's death. Adverse effects were recorded prospectively with each cycle of chemotherapy, and reported using CTCAE version 3.0 (http://ctep.cancer.gov).

\section{Pathology and tumour assessment}

Patients were diagnosed as having an NET both morphologically and immunohistochemically. Ki-67 index was assessed by an independent pathologist using the MIB1 antibody and counting the percentage of positive tumour cells in 2000 neoplastic cells in the area of highest labelling, and mitotic index (MI) was reported as the number of mitoses per 10 high-power fields (HPFs) in areas of highest mitotic activity. Tumours were graded using the proposed grading system of Rindi et al (2006). Briefly tumours were graded as grade 1 (low) with MI $<2$ per $10 \mathrm{HPFs}$ and/or Ki-67 $\leqslant 2 \%$, grade 2 (intermediate) with MI 2-20 per $10 \mathrm{HPFs}$ and/or Ki-67 3-20\% and grade 3 (high) with MI $>20$ per $10 \mathrm{HPFs}$ and Ki-67 $>20 \%$. Tumour somatostatin receptor expression was determined by indium octreotide scintigraphy, urinary 5-hydroxyindoleacetic acid (5HIAA) was assessed by $24 \mathrm{~h}$ urine collection using standard laboratory methods, and chromogranin A (CGA) was measured using standard laboratory methods and reported as abnormal at $>60 \mathrm{Ul}^{-1}$. Baseline blood markers were measured within 3 months of the start of chemotherapy.

\section{Statistical analysis}

Statistical analyses were performed using STATA version 10 (Stata Corp. LP, College Station, TX, USA). Median TTR, duration of response, time to progression and OS were calculated using Kaplan-Meier survival analysis.

We explored potential markers that were predictive of response in relation to treatment, or prognostic in terms of overall or PFS. Ki-67 index and MI were initially examined as continuous data but because they were not normally distributed (even when transformed onto a logarithmic scale) they were divided up into approximate tertiles and analysed as categorical variables. CGA was analysed in two groups; above and below the upper limit of the normal (ULN) range. Tumour markers were analysed in two groups; above and below $1.5 \times$ ULN, which we have previously reported as a prognostic cut off for $\alpha$-fetoprotein (AFP) and human chorionic gonadotropin (HCG; Shah et al, 2008). Fisher's exact test and $\chi^{2}$-test for trend were used for predictive markers and data were reported for all eligible patients. Cox regression analyses allowing for grade, performance status, primary site (pancreatic or non-pancreatic) and age at the start of chemotherapy were performed for each factor and a hazard ratio and $99 \%$ confidence interval were calculated. $99 \%$ was chosen to allow for examination of several factors.

\section{RESULTS}

\section{Patient characteristics}

We treated 82 patients with a median age of 55 years (range 22-81 years) (Table 1). Primary tumour site was pancreatic in 49 patients (60\%), GI tract in 9 patients (11\%), lung in 8 patients (10\%), ovarian in 1 patient and unknown in 15 patients (18\%). Metastatic disease was present in $89 \%$ of patients and the liver was the most common secondary site occurring in $76 \%$. Previous systemic treatment included subcutaneous octreotide therapy, ${ }^{131} \mathrm{I}$ MIBG $(n=4),{ }^{90} \mathrm{Y}$ DOTA octreotide radionucleotide therapy $(n=3)$, arterial embolisation, interferon- $\alpha$, external beam radiotherapy and 57 patients (70\%) had no prior therapy (Table 1). At least three cycles of chemotherapy were given in $93 \%$ cases and $72 \%$ received at least six cycles. Six patients were treated with carboplatin AUC 5 due to a low GFR at baseline $(n=5)$ and poor cardiac function precluding appropriate pre-hydration $(n=1)$. A further six patients were switched from cisplatin to carboplatin because of emergent cisplatin-related toxicity.

\section{Adverse events}

Chemotherapy, in general, was well tolerated with adverse effects detailed in Table 2. The most common toxicity was fatigue 
Table I Clinicopathological features of patients

\begin{tabular}{|c|c|c|c|}
\hline Primary site & Pancreatic & Non-pancreatic & All \\
\hline Number & 49 & 33 & 82 \\
\hline Median age (range) & $54.9(24.4-81.6)$ & $57.4(22.2-67.7)$ & $55.4(22.2-81.6)$ \\
\hline Male & 27 & 15 & 42 \\
\hline Female & 22 & 18 & 40 \\
\hline \multicolumn{4}{|l|}{ Performance status } \\
\hline $0-1$ & 44 & 27 & 71 \\
\hline$\geqslant 2$ & 5 & 6 & 11 \\
\hline \multicolumn{4}{|l|}{ Site } \\
\hline Lung & - & 8 & - \\
\hline Gl tract & - & 9 & - \\
\hline Ovarian & - & 1 & - \\
\hline Unknown & - & 15 & - \\
\hline \multicolumn{4}{|l|}{ Differentiation } \\
\hline Well & 36 & 21 & 57 \\
\hline Poorly & 9 & 9 & 18 \\
\hline \multicolumn{4}{|l|}{ Grade } \\
\hline $\operatorname{Low}(I)$ & 4 & 4 & 8 \\
\hline Intermediate (2) & 31 & 16 & 47 \\
\hline High (3) & 5 & 10 & 15 \\
\hline Unknown & 9 & 3 & 12 \\
\hline \multicolumn{4}{|l|}{ Sites of metastases } \\
\hline None & 5 & 4 & 9 \\
\hline Liver & 41 & 21 & 62 \\
\hline Lymph node & 13 & 14 & 27 \\
\hline Lung & 7 & 7 & 14 \\
\hline Bone & 6 & 5 & || \\
\hline Other & 10 & 6 & 16 \\
\hline \multicolumn{4}{|l|}{ Prior systemic therapy } \\
\hline None & 33 & 24 & 57 \\
\hline Radionucleotide & 4 & 3 & 7 \\
\hline Embolisation & 3 & 0 & 3 \\
\hline Interferon & 2 & 1 & 3 \\
\hline Octreotide & 8 & 7 & 15 \\
\hline Radiotherapy & 0 & 1 & 1 \\
\hline \multicolumn{4}{|l|}{ Octreotide scintigraphy } \\
\hline Positive & 39 & 18 & 57 \\
\hline Negative & 9 & II & 20 \\
\hline \multicolumn{4}{|l|}{ 5HIAA urine } \\
\hline Positive & 4 & 7 & 11 \\
\hline Negative & 21 & 16 & 37 \\
\hline \multicolumn{4}{|l|}{ Chromogranin A } \\
\hline Positive $\left(>60 \cup I^{-1}\right)$ & 17 & 10 & 27 \\
\hline Negative $\left(\leq 60 \cup I^{-1}\right)$ & 9 & 10 & 19 \\
\hline \multicolumn{4}{|l|}{ Tumour type } \\
\hline Non-functional & 38 & 31 & 69 \\
\hline Gastrinoma & 5 & 0 & 5 \\
\hline Glucagonoma & 4 & I & 5 \\
\hline Somatostatinoma & I & I & 2 \\
\hline Vipoma & 1 & 0 & I \\
\hline
\end{tabular}

Abbreviations: $\mathrm{Gl}=$ gastrointestinal; 5HIAA = 5-hydroxyindoleacetic acid.

occurring in $73 \%$ of patients but with grade 3 fatigue in only $7 \%$ patients. Grade 3 or 4 side effects were uncommon, with the highest incidence being neutropaenia (28\%) although grade $3 / 4$ infection only occurred in $7 \%$. There was no grade $3 / 4$ renal toxicity and only $2 \%$ had grade $3 / 4$ neuropathy. In contrast to doxorubicin-containing regimens FCiSt did not cause hair loss.
Table 2 Toxicity according to CTCAE version 3.0

\begin{tabular}{lrrrr}
\hline & \multicolumn{4}{c}{ Worst toxicity grade (no of patients) } \\
\cline { 2 - 5 } Toxicity & $\mathbf{I}$ & $\mathbf{2}$ & $\mathbf{3}$ & $\mathbf{4}$ \\
\hline Nausea & 23 & 22 & 10 & 2 \\
Vomiting & 12 & 15 & 12 & 2 \\
Fatigue & 25 & 29 & 6 & 0 \\
Diarrhoea & 12 & 9 & 6 & 2 \\
Neuropathy & 23 & 5 & 1 & 1 \\
Stomatitis & 17 & 7 & 1 & 0 \\
Infection & 6 & 8 & 3 & 3 \\
ANC & 8 & 19 & 21 & 2 \\
Haemoglobin & 27 & 16 & 6 & 0 \\
Renal & 5 & 5 & 0 & 0 \\
Platelet & 21 & 7 & 3 & 1 \\
\hline
\end{tabular}

Abbreviation: $\mathrm{ANC}=$ absolute neutrophil count.

There were no toxic deaths, although one patient died on treatment due to disease progression.

\section{Response assessment}

Of the 82 patients, 79 were assessable for response. The response rate for tumours of pancreatic origin was $38 \%$ (18 out of 47 patients) whereas that for non-pancreatic tumours was $25 \%$ (8 out of 32 patients) (Table 3 ). One patient with a grade 3 bronchial NET achieved a partial response after six cycles and went on to have his primary tumour and involved mediastinal lymph nodes resected. On histological examination there was no viable remaining tumour and he remains well and disease free 5 years after resection. Overall, objective response rate was 33\% $(n=26)$, with stable disease as best response in 51\% $(n=40)$, and progressive disease in $16 \%(n=13)$. Stable disease lasting more than 6 months occurred in $39 \%(n=31)$ of patients. The median TTR was 20 weeks (range 7-47 weeks) and the median duration of response was 36 weeks. Delayed response was observed in five patients (19\% of responding patients), with RECIST criteria for response not being met at the end of treatment CT scan but reached on subsequent follow-up CT scans while off treatment.

\section{Prediction of response}

We examined factors that predicted for response to chemotherapy (Table 3). We found no statistical difference in response rates between tumours with pancreatic primary and non-pancreatic primary sites ( $38 v s 25 \%$ respectively, $P=0.24$, Fisher's exact test). There was some evidence to suggest that histological grade predicted response to chemotherapy, with a higher response rate with higher histological grade $\left(P=0.02, \chi^{2}\right.$-test for trend). Of the five patients with delayed response to chemotherapy one had a high-grade tumour, three had intermediate-grade tumour and one had low-grade tumour.

We also assessed how well proliferative fraction, assessed with Ki-67, or MI predicted response. Overall there was a moderately strong correlation between MI and Ki-67 $(r=0.68, P<0.0001$, Spearman's correlation coefficient). We found the MI to be significantly associated $\left(P=0.008, \chi^{2}\right.$-test for trend) with response to chemotherapy, with response rates increasing from $15 \%$ for MI $0-1$ to $55 \%$ for $\mathrm{MI} \geqslant 5$.

There was some evidence to suggest that Ki-67 index may also predict response to chemotherapy (Table 3), although the difference in response rate between low, medium and high tertiles did not quite reach statistical significance $\left(P=0.019, \chi^{2}\right.$-test for trend). Similarly there was some evidence that poorly differentiated tumours had a higher response rate than welldifferentiated tumours $(P=0.046)$. 
Table 3 Response and predictive markers

\begin{tabular}{|c|c|c|c|c|c|c|}
\hline \multirow[b]{2}{*}{$\begin{array}{l}\text { Predictor } \\
\text { (normal } \\
\text { range) }\end{array}$} & \multicolumn{3}{|c|}{ Response } & \multirow[b]{2}{*}{$\begin{array}{l}\text { PR } \\
\text { (\%) }\end{array}$} & \multirow{2}{*}{$\begin{array}{l}\text { Fisher's } \\
\text { exact test } \\
P \text {-value }\end{array}$} & \multirow{2}{*}{$\begin{array}{l}\chi^{2} \text {-test } \\
\text { for trend } \\
P \text {-value }\end{array}$} \\
\hline & PR & SD & PD & & & \\
\hline All $(n=79)$ & 26 & 40 & 13 & 33 & & \\
\hline \multicolumn{7}{|l|}{ Primary } \\
\hline Pancreas & 18 & 24 & 5 & 38 & $0.24^{*}$ & - \\
\hline Non-pancreas & 8 & 16 & 8 & 25 & & - \\
\hline Unknown & 3 & 7 & 4 & 21 & & \\
\hline Lung & 2 & 4 & 2 & 25 & & \\
\hline Gl tract & 2 & 5 & 2 & 22 & & \\
\hline Ovarian & I & 0 & 0 & 100 & & \\
\hline \multicolumn{7}{|l|}{ Octreotide } \\
\hline Positive & 19 & 32 & 5 & 34 & 0.99 & - \\
\hline Negative & 6 & 5 & 7 & 33 & & - \\
\hline \multicolumn{7}{|l|}{$5 H I A A$} \\
\hline Positive & 2 & 6 & 2 & 20 & 0.99 & - \\
\hline Negative & 10 & 19 & 7 & 28 & & - \\
\hline \multicolumn{7}{|c|}{$\operatorname{AFP}\left(0-11.3 \mathrm{ng} \mathrm{m}^{-1}\right)$} \\
\hline$\leqslant 16$ & 10 & 22 & 8 & 25 & 0.020 & - \\
\hline$>16$ & 9 & 5 & 0 & 64 & & \\
\hline \multicolumn{7}{|c|}{ HCG $\left(0-2.5 \mathrm{~m} / \cup \mathrm{ml}^{-1}\right)$} \\
\hline$\leqslant 4$ & 10 & 16 & 5 & 32 & 0.48 & - \\
\hline$>4$ & 5 & 5 & 1 & 46 & & - \\
\hline \multicolumn{7}{|c|}{ CA19.9 $\left(0-39 \cup_{\mathrm{ml}^{-1}}\right)$} \\
\hline$\leqslant 40$ & 7 & 17 & 5 & 24 & 0.23 & - \\
\hline$>40$ & 10 & 10 & 3 & 43 & & \\
\hline \multicolumn{7}{|c|}{ Chromogranin $\mathrm{A}\left(0-60 \mathrm{UI}^{-1}\right)$} \\
\hline$\leqslant 60$ & 6 & 12 & । & 32 & 0.99 & \\
\hline$>60$ & 9 & 13 & 3 & 36 & & \\
\hline \multicolumn{7}{|l|}{ Ki-67 (\%) } \\
\hline$\leqslant 9$ & 4 & 15 & 3 & 18 & 0.059 & 0.019 \\
\hline $10-24$ & 9 & 13 & 2 & 38 & & \\
\hline$\geqslant 25$ & 12 & 6 & 5 & 52 & & \\
\hline \multicolumn{7}{|c|}{ Mitosis per $10 \mathrm{HPF}$} \\
\hline $0-1$ & 3 & 14 & 3 & 15 & 0.032 & 0.008 \\
\hline $2-4$ & 7 & 13 & 4 & 29 & & \\
\hline$\geqslant 5$ & 11 & 5 & 4 & 55 & & \\
\hline \multicolumn{7}{|l|}{ WHO grade } \\
\hline । & । & 4 & 2 & 14 & 0.085 & 0.023 \\
\hline 2 & 15 & 25 & 6 & 33 & & \\
\hline 3 & 9 & 3 & 3 & 60 & & \\
\hline \multicolumn{7}{|l|}{ PS } \\
\hline $0-1$ & 22 & 36 & 10 & 32 & 0.99 & \\
\hline$\geqslant 2$ & 4 & 4 & 3 & 36 & & \\
\hline \multicolumn{7}{|l|}{ Age } \\
\hline$\leqslant 60$ & 20 & 27 & 10 & 35 & 0.60 & \\
\hline$>60$ & 6 & 13 & 3 & 27 & & \\
\hline \multicolumn{7}{|l|}{ Differentiation } \\
\hline Well & 15 & 30 & 9 & 26 & 0.046 & \\
\hline Poorly & 10 & 4 & 4 & 56 & & \\
\hline
\end{tabular}

Abbreviations: $\quad \mathrm{Gl}=$ gastrointestinal; $\quad 5 \mathrm{HIAA}=5$-hydroxyindoleacetic $\quad$ acid $\mathrm{HCG}=$ human chorionic gonadotropin; HPF = high-power field; PD = progressive disease; $P R=$ partial response; $P S=$ performance status; $S D=$ stable disease; $\mathrm{WHO}=$ World Health Organization. ${ }^{*}$ Comparing pancreatic vs non-pancreatic
Of the tumour markers examined, there was some evidence that AFP above $16 \mathrm{ng} \mathrm{ml}^{-1}$ may be predictive of response (64 vs $25 \%$ $P=0.02$ ) whereas elevated $\beta$-HCG, CA19-9 and CGA were uninformative.

\section{Survival}

Patients were followed up for a median of 45 months. The 1- and 2-year survival was $76.7 \%$ (95\% CI 66-84.5) and $65.5 \%$ (95\% CI $54.1-74.7)$ respectively and the median OS was 31.5 months (Figure 1A). The 1- and 2-year PFS was 43.0\% (95\% CI 31.8-53.6) and $18.3 \%$ (95\% CI $10.3-28.1$ ) and median PFS was 9.1 months (Figure 1B). There was some evidence to suggest that performance status $(>1)$, non-pancreatic primary and poorly differentiated tumours (Figure 1C) may have been associated with a worse OS whereas age was not prognostic (Table 4). Hazard ratios and $99 \%$ CIs, adjusted for age, performance status, primary site and grade, were calculated for each potential prognostic factor (Table 5). A baseline CGA of $>60 \mathrm{Ul}^{-1}$ appeared to be strongly predictive of a worse OS (Figure 1D), with the hazard ratio for patients in the higher group reaching more than six times that of the patients in the lower group (Table 5). Ki-67 and MI were adjusted for performance status, age and primary site only (as tumour grade is based on their values). There was also evidence to suggest that both a high $\mathrm{MI}(\geqslant 5)$ and $\mathrm{Ki}-67(>25 \%)$ were strongly associated with poorer OS although neither quite reached statistical significance ( $P=0.017$, for both; Table 5; Figures $1 \mathrm{D}$ and E). Elevated $\alpha$-fetoprotein, $\beta$-HCG and CA19-9 levels do not seem to be prognostic.

\section{DISCUSSION}

In this study we report encouraging anti-tumour activity with acceptable toxicity using a novel combination of 5-fluorouracil, streptozocin and cisplatin for the treatment of advanced NETs. The overall disease control rate at 6 months was $72 \%$ with a median time to progression of 9.1 months and a median OS of 31.5 months, all of which compares favourably with previously reported large streptozocin-based regimens (Moertel et al, 1980, 1992; Engstrom et al, 1984; Kouvaraki et al, 2004; Sun et al, 2005). Pancreatic NETS had a higher response rate than non-pancreatic NETs (38 vs 25\%) and although this was not statistically significant, the trend is consistent with other studies. Importantly we found that one-fifth of responding patients had a delayed response, achieving stable disease at their end of treatment scan but partial response during subsequent follow-up while off treatment. A similar observation was made by Kouvaraki et al (2004) who reported a comparable median TTR of 4 months for fluorouracil, doxorubicin and streptozocin in the treatment of pancreatic NETs. However in that series chemotherapy was continued for up to 15.5 months and the authors argued that late response was a justification to continue chemotherapy until progression. In contrast our study data suggest that delayed response occurs even in the absence of ongoing chemotherapy and reflects the distinct biology of these tumours. This finding underlines the importance of longer-term follow-up imaging to define response accurately.

The FCiSt regimen was generally well tolerated. In contrast to previous studies, we have used an outpatient, 1 day, three weekly schedule using $1000 \mathrm{mg} \mathrm{m}^{-2}$ streptozocin rather than the 4-500 $\mathrm{mg} \mathrm{m}^{-2} 5$-day regimen, thereby improving patient convenience without compromising efficacy. It is notable that the combination of two nephrotoxic agents, streptozocin and cisplatin, used according to our schedule did not cause any grade 3-4 renal toxicity. Concern about renal toxicity for cisplatin in the field of NETs was raised by two studies (Moertel et al, 1991; Fjallskog et al, 2001) in which cisplatin was administered as a continuous infusion $45 \mathrm{mg} \mathrm{m}^{-2}$ per day for 2 days. Some patients in these studies had 
A

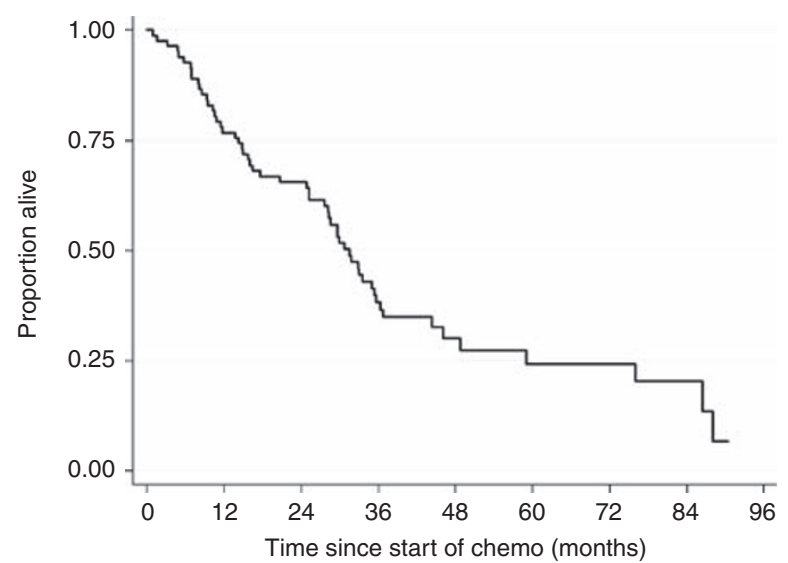

Number at risk
49

12

7

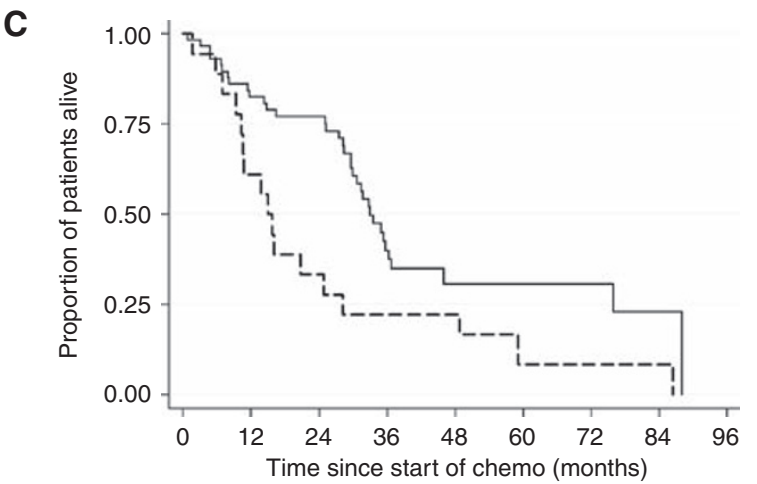

Number at risk

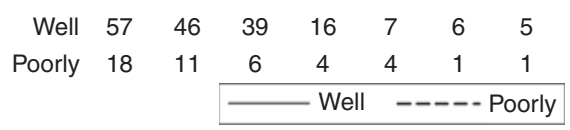

E

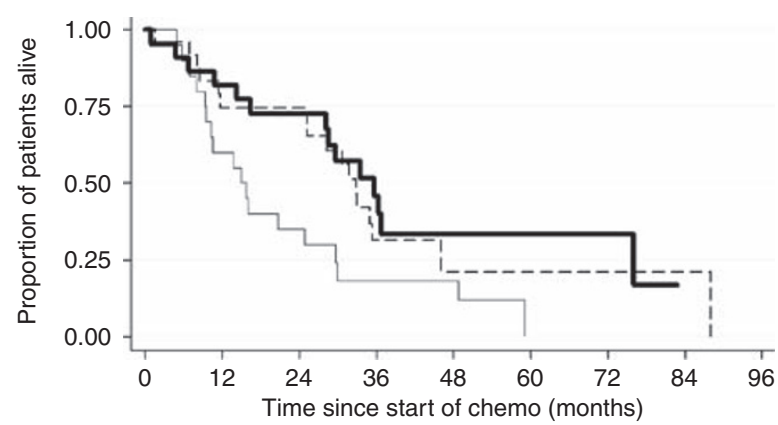

Number at risk

$$
\begin{aligned}
& \text { MI: } 0-1 \quad 22 \quad 18 \quad 15 \quad 8 \quad 4 \\
& \text { MI: } 2-4 \quad 24 \quad 17 \quad 16 \quad 6 \quad 2 \\
& \text { MI: } \geqslant 5 \quad 20 \quad 12 \quad 7 \quad 3 \quad 3 \\
& \begin{array}{l}
\text { MI: } 0-1 \quad-----M I: 2-4 \\
\text { MI: } \geqslant 5
\end{array}
\end{aligned}
$$

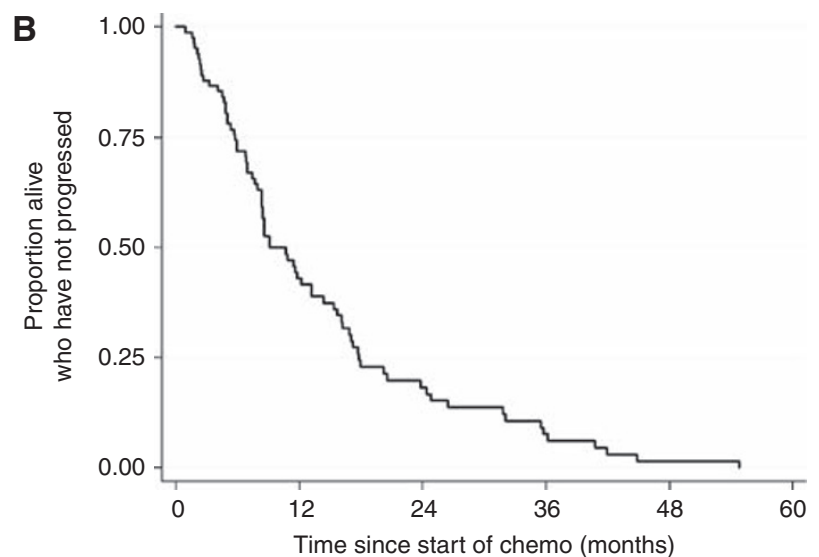

Number at risk

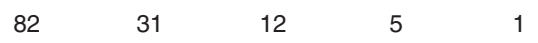

D

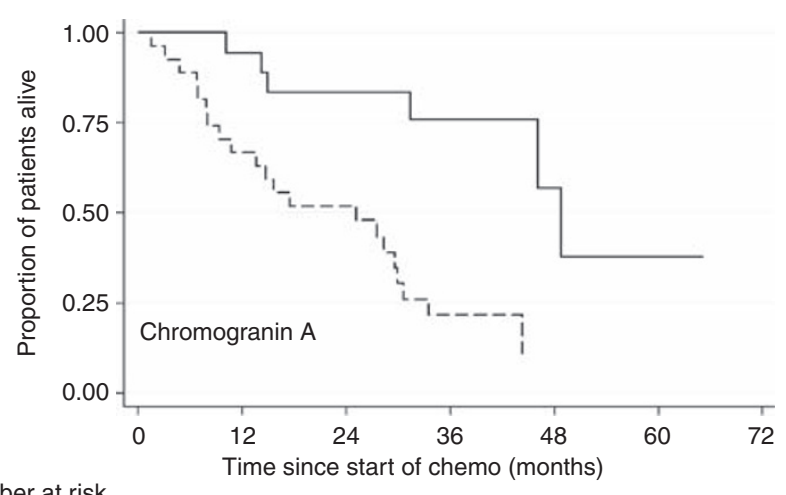

Number at risk

Chromogranin A $\leqslant \begin{array}{lllll}60 & 19 & 17 & 13 & 7\end{array}$

Chromogranin A $>\begin{array}{llllll}60 & 27 & 18 & 13 & 5\end{array}$

Chromogranin $A \leqslant 60 \quad----\cdot$ Chromogranin $A>60$

$\mathbf{F}$

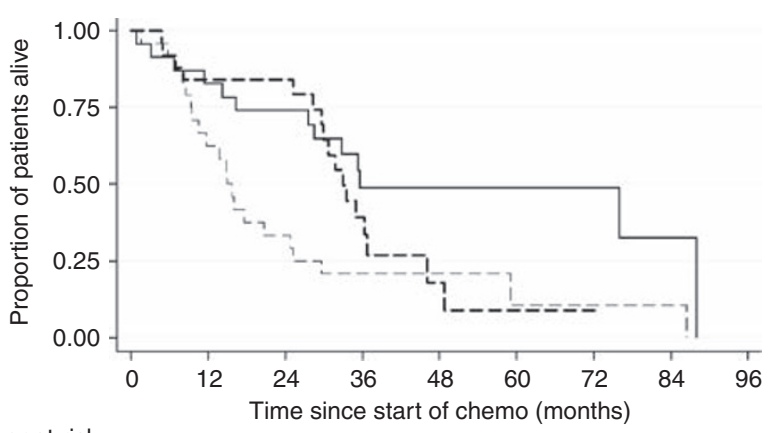

Number at risk

$\begin{array}{lllccc}\text { Ki- } 67<10 & 23 & 19 & 17 & 9 & 5 \\ 10-24 & 25 & 20 & 18 & 7 & 2 \\ \text { Ki-67 } \geqslant 25 & 24 & 15 & 8 & 4 & 3\end{array}$

Figure I Overall survival $(\mathbf{A})$ and progression-free survival (B). Overall survival according to differentiation status (C), normal or elevated serum chromogranin A (D) mitotic index (MI) (E) Ki-67 index (F).

already received high-dose streptozocin and had documented renal impairment. By contrast our patients were chemonaive and were required to have a baseline GFR above $60 \mathrm{ml} \mathrm{min}^{-1}$ as outlined in the methods. Similar to the study by Mitry et al (1999), who reported minimal renal toxicity for a $2 \mathrm{~h}$ infusion of cisplatin at a dose of $100 \mathrm{mg} \mathrm{m}^{-2}$, we experience minimal toxicity using a short infusion at $70 \mathrm{mg} \mathrm{m}^{-2}$.
The prognostic factors associated with survival in patients with NETs have been well defined and include grade, stage, primary site, sex, age and race (Yao et al, 2008) and, in patients treated with chemotherapy, the extent of liver metastasis (Kouvaraki et al, 2004). In our selected cohort of patients CGA was found to be prognostic for OS and there was evidence to suggest that Ki-67 index and MI may also be prognostic but in this 
Table 4 Univariable analysis for prognostic indicators

\begin{tabular}{|c|c|c|c|c|}
\hline Risk factor & $\begin{array}{l}\text { PFS HR } \\
(99 \% \mathrm{Cl})\end{array}$ & $P$-value & $\begin{array}{c}\text { OS HR } \\
(99 \% \mathrm{Cl})\end{array}$ & $P$-value \\
\hline $\begin{array}{l}\text { Age (for an increase } \\
\text { of } 10 \text { years) }\end{array}$ & $1.05(0.80-1.39)$ & 0.63 & $1.15(0.84-1.59)$ & 0.24 \\
\hline \multicolumn{5}{|l|}{ Grade } \\
\hline 1 & 1.00 & \multirow[t]{3}{*}{0.39} & 1.00 & \multirow{3}{*}{0.03} \\
\hline 2 & $0.73(0.27-1.99)$ & & $0.45(0.15-1.36)$ & \\
\hline 3 & $1.09(0.34-3.44)$ & & $1.03(0.30-3.52)$ & \\
\hline \multicolumn{5}{|l|}{ PS } \\
\hline $0-1$ & 1.00 & \multirow[t]{2}{*}{0.33} & 1.00 & \multirow[t]{2}{*}{0.038} \\
\hline$>1$ & $1.40(0.59-3.28)$ & & $2.32(0.89-6.05)$ & \\
\hline \multicolumn{5}{|l|}{ Primary site } \\
\hline Non-pancreatic & 1.00 & \multirow[t]{2}{*}{0.18} & 1.00 & \multirow[t]{2}{*}{0.03} \\
\hline Pancreatic & $0.72(0.38-1.35)$ & & $0.54(0.26-1.11)$ & \\
\hline \multicolumn{5}{|l|}{ Differentiation } \\
\hline Well & 1.00 & \multirow[t]{2}{*}{0.44} & 1.00 & \multirow[t]{2}{*}{0.016} \\
\hline Poorly & $1.26(0.60-2.67)$ & & $2.16(0.99-4.7 I)$ & \\
\hline
\end{tabular}

Abbreviations: $\quad H R=$ hazard ratio; $O S=$ overall survival; $P F S=$ progression-free survival; PS = performance status.

Table 5 Multivariable analysis for prognostic markers

\begin{tabular}{|c|c|c|c|c|}
\hline Marker & $\begin{array}{l}\text { PFS HR } \\
(99 \% \mathrm{Cl})\end{array}$ & $P$-value & $\begin{array}{l}\text { OS HR } \\
(99 \% \mathrm{Cl})\end{array}$ & $P$-value \\
\hline \multicolumn{5}{|l|}{$\operatorname{AFP}(n=57)$} \\
\hline $\begin{array}{l}\leqslant 16 \mathrm{ng} \mathrm{ml}^{-1} \\
>16 \mathrm{ng} \mathrm{ml}^{-1}\end{array}$ & $\begin{array}{c}1.00 \\
1.30(0.50-3.42)\end{array}$ & 0.49 & $\begin{array}{c}1.00 \\
1.25(0.45-3.52)\end{array}$ & 0.58 \\
\hline \multicolumn{5}{|l|}{ HCG $(n=45)$} \\
\hline $\begin{array}{l}\leqslant 4 \mathrm{mlUml}^{-1} \\
>4 \mathrm{mlUml}^{-1}\end{array}$ & $\begin{array}{c}1.00 \\
0.72(0.21-2.45)\end{array}$ & 0.17 & $\begin{array}{c}1.00 \\
2.35(0.54-10.21)\end{array}$ & 0.15 \\
\hline \multicolumn{5}{|l|}{ CA19.9 $(n=55)$} \\
\hline $\begin{array}{l}\leqslant 40 \\
>40\end{array}$ & $\begin{array}{c}1.00 \\
0.49(0.18-1.35)\end{array}$ & 0.06 & $\begin{array}{c}1.00 \\
0.81(0.28-2.33)\end{array}$ & 0.60 \\
\hline \multicolumn{5}{|c|}{ Chromogranin A $(n=46)$} \\
\hline $\begin{array}{l}\leqslant 60 \cup \mathrm{I}^{-1} \\
>60 \mathrm{UI}^{-1}\end{array}$ & $\begin{array}{c}1.00 \\
2.77(0.88-8.66)\end{array}$ & 0.017 & $\begin{array}{c}1.00 \\
6.77(1.26-36.50)\end{array}$ & $<0.001$ \\
\hline \multicolumn{5}{|l|}{$K i-67 \%(n=72) *$} \\
\hline $\begin{array}{l}<9 \\
10-24 \\
\geqslant 25\end{array}$ & $\begin{array}{c}1.00 \\
1.06(0.43-2.59) \\
1.51(0.65-3.51)\end{array}$ & 0.38 & $\begin{array}{c}1.00 \\
1.18(0.39-3.55) \\
2.59(0.98-6.83)\end{array}$ & 0.017 \\
\hline \multicolumn{5}{|c|}{ Mitosis per 10 HPF $(\mathrm{n}=66)^{*}$} \\
\hline $0-1$ & 1.00 & 0.04 & 1.00 & 0.017 \\
\hline $2-4$ & $1.04(0.43-2.5 \mathrm{I})$ & & $1.29(0.49-3.36)$ & \\
\hline$\geqslant 5$ & $2.29(0.9 \mid-5.78)$ & & $2.99(1.07-8.36)$ & \\
\hline
\end{tabular}

Abbreviations: $\quad$ AFP $=\alpha$-fetoprotein; $\quad$ HCG $=$ human chorionic gonadotropin $\mathrm{HPF}=$ high-power field; $\mathrm{HR}=$ hazard ratio; $\mathrm{OS}=$ overall survival; $\mathrm{PFS}=$ progressionfree survival. Hazard ratios adjusted for age, grade, primary site and performance status. *Adjusted for performance status, primary site and age.

sample of patients, they did not quite reach statistical significance. Unusually, patients with a pancreatic primary tumour had a better survival than those with a non-pancreatic primary tumour. The likely explanation for this observation is that in our series, selected for chemotherapy, $30 \%$ of patients with non-pancreatic primary tumour had high-grade tumours whereas for patients with pancreatic primary tumour the proportion was only $10 \%$ and grade was a dominant prognostic factor (Pape et al, 2008b; Yao et al, 2008).
Less well defined in the literature are the factors that predict response to chemotherapy. Assessment of the proliferation fraction as measured by MIB1 staining of Ki-67 $>10 \%$ has been proposed as a means of selecting patients for cytotoxic treatment but it is acknowledged that clear evidence for this strategy is lacking (Vilar et al, 2007). We have used our large, homogeneously treated, consecutive series to examine for predictors of response. In our analysis there was a trend for response rate to increase with a higher Ki-67 index but even in those with $\mathrm{Ki}-67 \leqslant 9 \%$ the response rate was $18 \%$. Hence if $\mathrm{Ki}-67$ is to be used to select patients for chemotherapy the cut off remains to be defined but our study data suggest that it should be less than $10 \%$. MI and tumour grade were good predictors of response with highergrade tumours and those with a high mitotic rate having a higher response rate. To the best of our knowledge this is the first systematic analysis of MI and Ki-67 index as predictors of response and prognosis for NETs in patients treated with chemotherapy.

We have previously reported that elevations of AFP and $\beta$-HCG $(>1.5 \times \mathrm{ULN})$ are associated with a poorer survival in NETs (Shah et al, 2008). In contrast neither of these markers was prognostic in the current cohort treated with chemotherapy. Intriguingly an elevated AFP may be associated with a higher response rate and one can speculate that treating these patients with chemotherapy improves their survival such that the prognostic value of the baseline measurement is obscured. Neither serum CGA, nor urinary 5HIAA nor somatostatin receptor expression had any predictive value.

Importantly, we were unable to identify a group of patients who did not respond to chemotherapy. In this series, $14 \%$ (1 out of 7 ) of the few patients with low-grade tumours responded to chemotherapy, and $15 \%$ ( 3 out of 20 ) of tumours with an MI of $<2$ (low-grade MI) responded, challenging the view that these tumours are resistant to chemotherapy. However, there are a number of factors that should be considered in interpreting this data. Potentially this finding may reflect tumour heterogeneity not captured by percutaneous biopsy, with the response in 'low-grade' tumours reflecting unsampled highergrade tumour that responds to chemotherapy. It is also possible that histologically low-grade tumours at diagnosis have become highergrade tumours by the time treatment is initiated. Finally, the late responding nature of many low/intermediate-grade tumours, which we have identified in this study, suggests that chemosensitivity of these tumours may have previously been underestimated.

Non-streptozocin-based chemotherapy regimens have been explored in NETs and while agents such as paclitaxel (Ansell et al, 2001) and gemcitabine (Kulke et al, 2004) appear to be ineffective, there are encouraging data for temozolamide in uncontrolled phase II trials (Kulke et al, 2006; Ekeblad et al, 2007). A significant difficulty in comparing reports for different chemotherapy regimens in NETs relates to heterogeneity of this patient population. Survival times can be as short as 5 months for poorly differentiated metastatic tumours or as long as 223 months for those with localised well-differentiated tumours (Yao et al, 2008). Here we have shown the predictive value of grade, MI and AFP, and the prognostic importance of Ki-67, MI and CGA in a cohort of patients treated, first line, with a single chemotherapy regimen. Accurate reporting of patient and tumour characteristics is therefore essential but randomised trials are also required to define the optimal regimen. In the UK, the most widely used combination chemotherapy for NETs is streptozocin and a fluoropyramidine (SF) and, on the basis of the data presented here, the UKCRN is currently recruiting to a randomised phase II trial of SF with/without cisplatin.

\section{ACKNOWLEDGEMENTS}

DH, RB and TM were partly funded by UCLH/UCL Department of Health's NIHR Biomedical Research Centres funding scheme. We thank Alison Prax for invaluable administrative assistance during the collection of data. 


\section{REFERENCES}

Ansell SM, Pitot HC, Burch PA, Kvols LK, Mahoney MR, Rubin J (2001) A phase II study of high-dose paclitaxel in patients with advanced neuroendocrine tumors. Cancer 91(8): 1543-1548

Bukowski RM, Johnson KG, Peterson RF, Stephens RL, Rivkin SE, Neilan B, Costanzi JH (1987) A phase II trial of combination chemotherapy in patients with metastatic carcinoid tumors. A Southwest Oncology Group Study. Cancer 60(12): 2891-2895

Cheng PN, Saltz LB (1999) Failure to confirm major objective antitumor activity for streptozocin and doxorubicin in the treatment of patients with advanced islet cell carcinoma. Cancer 86(6): 944-948

Ekeblad S, Sundin A, Janson ET, Welin S, Granberg D, Kindmark H, Dunder K, Kozlovacki G, Orlefors H, Sigurd M, Oberg K, Eriksson B, Skogseid B (2007) Temozolomide as monotherapy is effective in treatment of advanced malignant neuroendocrine tumors. Clin Cancer Res 13(10): 2986-2991

Engstrom PF, Lavin PT, Moertel CG, Folsch E, Douglass Jr HO (1984) Streptozocin plus fluorouracil versus doxorubicin therapy for metastatic carcinoid tumor. J Clin Oncol 2(11): 1255-1259

Eriksson B, Skogseid B, Lundqvist G, Wide L, Wilander E, Oberg K (1990) Medical treatment and long-term survival in a prospective study of 84 patients with endocrine pancreatic tumours. Cancer 65(9): 1883 - 1890

Fjallskog ML, Granberg DP, Welin SL, Eriksson C, Oberg KE, Janson ET, Eriksson BK (2001) Treatment with cisplatin and etoposide in patients with neuroendocrine tumors. Cancer 92(5): $1101-1107$

Kouvaraki MA, Ajani JA, Hoff P, Wolff R, Evans DB, Lozano R, Yao JC (2004) Fluorouracil, doxorubicin, and streptozocin in the treatment of patients with locally advanced and metastatic pancreatic endocrine carcinomas. J Clin Oncol 22(23): $4762-4771$

Kulke MH, Kim H, Clark JW, Enzinger PC, Lynch TJ, Morgan JA, Vincitore M, Michelini A, Fuchs CS (2004) A phase II trial of gemcitabine for metastatic neuroendocrine tumors. Cancer 101(5): 934-939

Kulke MH, Stuart K, Enzinger PC, Ryan DP, Clark JW, Muzikansky A Vincitore M, Michelini A, Fuchs CS (2006) Phase II study of temozolomide and thalidomide in patients with metastatic neuroendocrine tumors. J Clin Oncol 24(3): 401-406

Mitry E, Baudin E, Ducreux M, Sabourin JC, Rufie P, Aparicio T, Aparicio T, Lasser P, Elias D, Duvillard P, Schlumberger M, Rougier P (1999) Treatment of poorly differentiated neuroendocrine tumours with etoposide and cisplatin. Br J Cancer 81(8): 1351-1355

Moertel CG, Hanley JA, Johnson LA (1980) Streptozocin alone compared with streptozocin plus fluorouracil in the treatment of advanced islet-cell carcinoma. N Engl J Med 303(21): 1189-1194
Moertel CG, Kvols LK, O’Connell MJ, Rubin J (1991) Treatment of neuroendocrine carcinomas with combined etoposide and cisplatin. Evidence of major therapeutic activity in the anaplastic variants of these neoplasms. Cancer 68(2): 227-232

Moertel CG, Lefkopoulo M, Lipsitz S, Hahn RG, Klaassen D (1992) Streptozocin-doxorubicin, streptozocin-fluorouracil or chlorozotocin in the treatment of advanced islet-cell carcinoma. $N$ Engl J Med 326(8): $519-523$

Pape UF, Berndt U, Mueller-Nordhorn J, Boehmig M, Roll S, Koch M, Willich S, Wiedenmann B (2008a) Prognostic factors of long-term outcome in gastroenteropancreatic neuroendocrine tumours. Endocr Relat Cancer 15(4): 1083 - 1097

Pape UF, Jann H, Muller-Nordhorn J, Bockelbrink A, Berndt U, Willich SN, Koch M, Rocken C, Rindi G, Wiedenmann B (2008b) Prognostic relevance of a novel TNM classification system for upper gastroenteropancreatic neuroendocrine tumors. Cancer 113(2): 256-265

Rindi G, Kloppel G, Alhman H, Caplin M, Couvelard A, de Herder WW, Erikssson B, Falchetti A, Falconi M, Komminoth P, Korner M, Lopes JM, McNicol AM, Nilsson O, Perren A, Scarpa A, Scoazec JY, Wiedenmann B (2006) TNM staging of foregut (neuro)endocrine tumors: a consensus proposal including a grading system. Virchows Arch 449(4): 395-401

Shah T, Srirajaskanthan R, Bhogal M, Toubanakis C, Meyer T, Noonan A, Witney-Smith C, Amin T, Bhogal P, Sivathasan N, Warner B, Hochhauser D, Caplin ME (2008) Alpha-fetoprotein and human chorionic gonadotrophin-beta as prognostic markers in neuroendocrine tumour patients. Br J Cancer 99(1): $72-77$

Sun W, Lipsitz S, Catalano P, Mailliard JA, Haller DG (2005) Phase II/III study of doxorubicin with fluorouracil compared with streptozocin with fluorouracil or dacarbazine in the treatment of advanced carcinoid tumors: Eastern Cooperative Oncology Group Study E1281. J Clin Oncol 23(22): $4897-4904$

Toumpanakis C, Meyer T, Caplin ME (2007) Cytotoxic treatment including embolization/chemoembolization for neuroendocrine tumours. Best Pract Res Clin Endocrinol Metab 21(1): 131 - 144

Vilar E, Salazar R, Perez-Garcia J, Cortes J, Oberg K, Tabernero J (2007) Chemotherapy and role of the proliferation marker Ki-67 in digestive neuroendocrine tumors. Endocr Relat Cancer 14(2): $221-232$

Yao JC, Hassan M, Phan A, Dagohoy C, Leary C, Mares JE, Abdalla EK, Fleming JB, Vauthey JN, Rashid A, Evans DB (2008) One hundred years after 'carcinoid': epidemiology of and prognostic factors for neuroendocrine tumors in 35825 cases in the United States. J Clin Oncol 26(18): 3063-3072 